\title{
Pharmacognostic Evaluation and Acute Toxicity Test of the Formulated Tisane Powder of Gallant Soldier (Galinsoga parviflora Cav., Asteraceae) Aerial Parts from Benguet, Philippines
}

\author{
JG Badilla*, MLC Fiangaan
}

\section{JG Badilla*, MLC Fiangaan}

Department of Pharmacy, School of Natural Sciences, Saint Louis University, Baguio City, PHILIPPINES.

\section{Correspondence \\ JG Badilla}

Department of Pharmacy, School of Natura Sciences, Saint Louis University, Baguio

City, PHILIPPINES

E-mail: jonieverbadilla@gmail.com

Orcid: https://orcid.org/0000-0003-14549195

History

- Submission Date: 23-11-2021;

- Review completed: 16-12-2021;

- Accepted Date: 05-01-2022.

DOI : 10.5530/pj.2022.14.25

Article Available online http://www.phcogj.com/v14/i1

\section{Copyright}

(C) 2022 Phcogj.Com. This is an openaccess article distributed under the terms of the Creative Commons Attribution 4.0 International license.

\begin{abstract}
Background: Galinsoga parviflora is a medicinal plant traditionally used to manage and treat various health conditions though the dearth of its scientific report on its pharmacognostic and safety profile remains. Objective: This study is designed to delineate the pharmacognostic and safety parameters of G. parviflora to ensure its authenticity, purity, quality, and safety. Methods: Qualitative and quantitative analysis, including physicochemical evaluation, macroscopic and microscopic characterization, phytochemical screening, and acute toxicity test, were carried out to establish the plant's diagnostic features and safety needed for its identification and standardization. For the Acute toxicity test, male and female rats were orally administered with aqueous extract at a single dose of $2000 \mathrm{mg} / \mathrm{kg}(\mathrm{n}=5 / \mathrm{sex})$ and $5000 \mathrm{mg} / \mathrm{kg}(\mathrm{n}=3 / \mathrm{sex}$ ). All experimental animals were critically observed individually for overt signs and symptoms of toxicity, behavioral changes, body weight changes, and mortality for 14 days. Results: The physicochemical characterization, macroscopic evaluation, morphometric determination, surface tissue examination, and powder analysis of the intact and powdered drug material revealed key diagnostic features and properties based on the stem, leaf, flower architecture, and pharmaceutical properties. The aqueous extract primarily contains alkaloids, glycosides, flavonoids, saponins, phytosterols, and tannins as its phytoconstituents. During the acute toxicity test, no toxicological response and mortality were observed on both doses. Conclusion: The present study provides vital architectural features and chemical characteristics of G. parviflora essential for establishing pharmacopoeial standards, especially in plantbased medicine. Additionally, the aqueous extract's oral dose of up to $5000 \mathrm{mg} / \mathrm{kg}$ is relatively safe as no significant evidence of treatment-related toxicity and mortality is seen.

Key Words: Acute toxicity, Microscopic, Physicochemical, Phytochemical, Standardization.
\end{abstract}

\section{INTRODUCTION}

Herbal medicine has been the foundation of traditional, complementary, and alternative medicine. Its use has been a secular tradition to different cultural communities throughout history and has reached extensive acceptability as a therapeutic agent for various health conditions. It includes preparations of biologically active natural products that consist mainly of herbs or herbal materials and are used to maintain health and manage various diseases. ${ }^{1}$ Depending on the region, practices, and inherent knowledge, plants can be prepared in multiple methods such as decoctions, macerates, infusions, and poultice. Further, they can be processed and taken in different ways and forms, including the whole herb, teas, syrup, essential oils, ointments, salves, rubs, capsules, and tablets containing a ground or powdered form of a raw herb or its extract. ${ }^{2}$

In retrospect, medications today have utilized plants as the basis for clinical and experimental research for drug bioactivity. About 17,000 higher plants and approximately 8,000 species are considered medicinal and are used in traditional healing practices by communities. ${ }^{3}$ As to plant sources, it was revealed that Asian and African continents share $56 \%$ and $17 \%$ of the medicinal herbal plant's distribution, respectively. ${ }^{4}$ Further, the World Health Organization (WHO) reports that more than $80 \%$ of the world population relies on traditional, alternative, and complementary medicine for their primary health care needs. ${ }^{5}$ This can be attributed to its availability, wide cultural acceptability, and perceived efficacy and safety. However, the unavailability of documentation and rigorous quality control acts as a key hindrance in the approval of herbal products as alternative medicine. ${ }^{6}$

Further, the lack of substantial scientific and clinical data on its quality, efficacy, and safety prevents it from being fully recognized and integrated into the modern health care system. Thus, with the upsurge in the number of people utilizing plant-based medicine, herbal preparations, especially those with significant potential for drug application, must be scientifically and clinically evaluated for their quality, purity, efficacy, and safety. The World Health Organization (WHO) has stressed the importance of conducting qualitative and quantitative analysis in characterizing plant samples, including physical and chemical characteristics, quantification of biomarkers or chemical markers, and fingerprint profiles. ${ }^{7}$ The emphasis is mainly on quality indices, including physicochemical evaluation, macro-and microscopic examination, qualitative and quantitative chemical evaluation, and chromatographic determination.

The continued incidence of adverse drug reactions from synthetic drugs coupled with financial constraints on remuneration for health care services and medications have driven people to revert to natural medicine. Additionally, the general

Cite this article: Badilla JG, Fiangaan MLC. Pharmacognostic Evaluation and Acute Toxicity Test of the Formulated Tisane Powder of Gallant Soldier (Galinsoga parviflora Cav., Asteraceae) Aerial Parts from Benguet, Philippines . Pharmacogn J. 2022;14(1): 193-204. 
misconception that herbal preparations are safe and devoid of toxic or adverse effects contributed to its wide acceptability; though, testing and monitoring remain minimal. This makes knowledge of their potential adverse effects very limited and identifying the safest and most effective therapies and promoting their rational use more difficult. ${ }^{5}$ Further, this notion has led people to improper use and unrestrained intake, resulting in poisoning and acute health problems. ${ }^{8}$ Therefore, quality control standards and safety evaluation of a traditionally used plant-based medicine are vital in view of the increasing demand and commercialization of herbal preparations.

Standardizing herbal medicines is vital to lay down technical standard parameters and specifications to ensure each herb's quality, safety, efficacy, and reproducibility before making it available. ${ }^{6,9}$ It provides scientific information's on the herbal preparation's quality to justify their acceptability and incorporation into the modern medicine system. In addition, the incorporation and maintenance of a set of quality assurance parameters in the production of herbal preparations provide an essential reference for its organoleptic, macroscopic, microscopic, physicochemical characteristics, phytochemicals present, and safety.

Galinsoga parviflora is a medicinal plant traditionally used in the management and treatment of various health conditions. Previous biological studies revealed that the plant possesses anti-oxidant, ${ }^{10-14}$ hepatoprotective, ${ }^{13}$ hypoglycemic, ${ }^{12-13}$ antimicrobial, ${ }^{13}$ cytotoxic activity $^{13}$ and anti-inflammatory ${ }^{15}$ activity but there is a dearth to its scientific report on its pharmacognostic and safety profile. Locally, the plant is regarded as a nuisance as it grows aggressively at high density and competes in the community's agricultural and floral crops. Its utilization and safety as conventional medicine for different conditions are poorly understood.

Medicinal plants still have a dominant role in the healthcare system, especially in developing countries with a long history of use. ${ }^{16}$ Over the years, its traditional practices and usage have covered more health areas and refined as applied. Currently, herbal preparation and production are gaining momentum towards product commercialization. However, for the majority of the traditionally used plants, the greatest challenge of standardizing quality, purity, efficacy, and safety remains unfounded. Thus, the current study aims to delineate the pharmacognostic parameters of the plant G. parviflora and lay down quality indexes for the herbal powder, generally on its physical, chemical, botanical, and toxicological characteristics.

\section{MATERIALS}

\section{Chemicals and reagents}

All reagents and chemicals including chloral hydrate, iodine, phloroglucinol, 1-naphthol, mercuric nitrate, sulfuric acid, glacial acetic acid, potassium hydroxide, and hydrochloric acid used were of analytical grade.

\section{Plant collection and identification}

Fresh aerial parts of G. parviflora were collected from the mountainside at Doag, Guinaoang, Mankayan, Benguet, Philippines in the early afternoon during March to May. The collection sites were at the following positions: Lat.016 $49^{\prime} 11^{\prime \prime}$ N, Lon. 120 49'29” E; Lat.016 $49^{\prime} 07^{\prime \prime}$ N, Lon. $120^{\circ} 49^{\prime} 26^{\prime \prime}$ E; and Lat.016 $49^{\prime} 08^{\prime \prime}$ N, Lon. 120 $49^{\prime} 24^{\prime \prime}$ E. Fresh and press dried sample was prepared and was authenticated by Dr. Jones T. Napaldet, a registered botanist from the University of the PhilippinesLos Banos (UP-LB).

\section{Animals}

Albino Sprague Dawley rats of both sexes were procured for the study. Female rats of 7-9 weeks weighing 150-180 grams were procured from the College of Veterinary Medicine (CVM), Benguet State University
(BSU). The male rats of 8-10 weeks were provided by a Bureau of Animal Industry (BAI)-certified breeder from Pampanga. All animals were housed at the Animal facility of CVM-BSU, maintained under standard laboratory conditions having a room temperature of $21 \pm 2^{\circ} \mathrm{C}$ with 12 hour light and dark cycle. The experimental protocol was based on the Organization for Economic and Cooperative Development (OECD) Guideline and guided by the PALAS Code of Practice for the Care and Use of Laboratory Animals in the Philippines and The International Guiding Principles of Biomedical Research Involving Animals, Council for International Organizations of Medical Sciences. The experimental usage of the animals was reviewed and approved by the University Ethics Committee of Saint Louis University, Baguio City, Philippines. This was further examined by the Department of Agriculture (DA) under the Bureau of Animal Industry (BAI) Region I - Philippines for the issuance of Animal Research Permit. All experimental procedures conducted were supervised by a duly licensed veterinarian.

\section{METHODS}

\section{Preparation of G. parviflora powder sample}

The collected G. parviflora aerial parts were garbled and washed with distilled water before oven-drying at $50^{\circ} \mathrm{C}$ for 8 hours. It was then comminuted using a mechanical blender to obtain a fine powder for analysis which was placed in an airtight jar and stored in a desiccator for the study. A fresh sample plant was used for the macroscopic analysis.

\section{Physicochemical analysis}

The methods used to determine the different physical and chemical properties of the powdered G. parviflora were based on the principle and procedures set by Knevel \& DiGangi, ${ }^{17}$ the WHO, ${ }^{7,18-19}$ and United States Pharmacopoeia (USP). ${ }^{20}$

\section{Botanical evaluation}

Microscopic evaluation and powder microscopy followed the guidelines set by the $\mathrm{WHO}^{7}$ and Evans. ${ }^{21}$

The macroscopic and organoleptic evaluations were conducted on fresh and powdered materials. The sample was evaluated based on its size, shape, taste, color, odor, and texture. Primary morphometric data of the plant's leaf size, flower size, and stem length were measured using a standard ruler and a vernier caliper.

Morphological examinations and powder microscopy in $10 \% \mathrm{w} / \mathrm{v}$ Potassium Hydroxide ${ }^{7}$ were observed using an OMAX microscope equipped with BestScope $e^{\infty}$ Digital LCD for photographic imaging. Cross-sections were prepared by freehand sectioning.

Quantitative microscopy to determine the stomatal number, stomatal density, palisade ratio, vein islet number, and vein termination number utilized a leaf section of fresh and cleared samples. Photomicrographs were taken using the Digital LCD, and the images were analyzed using Image J software.

\section{Extraction}

Two hundred (200) grams of the powdered material was infused in $8 \mathrm{~L}$ of distilled water at the onset of boiling $\left(75^{\circ} \mathrm{C}\right)$ and allowed to steep for 15 minutes. The sample was cooled and filtered. The filtrate was concentrated in a water bath at $75^{\circ} \mathrm{C}$.

\section{Phytochemical screening}

The method employed to screen for the secondary metabolites present in the aqueous extract of the sample plant (tisane brew) is adopted from Guevarra ${ }^{22}$ and De et al. ${ }^{23}$ with slight modifications to suit the conditions of the study. The results were then recorded as positive $(+)$ or negative (-), when the expected result occurs or not, respectively. 


\section{Acute toxicity test}

Healthy male and female Albino Sprague Dawley rats were used in the study following the Organization for Economic and Cooperative Development (OECD) guideline for acute oral toxicity tests, specifically the Main 425 Test: Acute Oral Toxicity-Up-and-Down Procedure (UDP). ${ }^{24}$

A duly licensed veterinarian verified the rats' health and had undergone five days of acclimatization before the study was initiated. All animals were fasted overnight (16 hours) but with free access to water and weighed before administering the sample extract. The animals were randomly divided into two groups ( $\mathrm{n}=10 ; 5$ males and 5 females). Group 1 (Acute Toxicity) received a limit dose of the GPA extract of $2 \mathrm{~g} / \mathrm{kg}$ BW, and Group 2 (Acute Toxicity) received a limit dose of the GPA extract of $5 \mathrm{~g} / \mathrm{kg}$ BW.

All experimental animals were critically observed individually for overt signs and symptoms of toxicity, behavioral changes, body weight changes, and mortality for the first thirty minutes and then hourly for 6 hours and then once every 24 hours for the next 14 days.

During the study period, clinical observations were made for mortality and pharmacologic-toxicologic effect (change in motor activity, ataxia rating, loss of righting reflex, analgesia, corneal and pinnal reflex, startle reaction, body tremors, fasciculations, convulsions, ptosis, enophthalmos, exophthalmos, chromadacryorrhea, ear blanching and hyperemia, salivation, Straub response, writhing, and Robichaud test). ${ }^{22}$ The $\mathrm{LD}_{50}$ should be greater than $5 \mathrm{~g} / \mathrm{kg}$ if three or more rats survived in Group 2 and is below $2 \mathrm{~g} / \mathrm{kg}$ if one or more rats died in Group 1. At the end of the experimental period, all animals were weighed and sacrificed by cervical dislocation for gross pathological examination.

\section{Treatment of data}

The results from the pharmacognostic and botanical evaluation were treated as descriptive terms. Morphometric data and other quantitative data were expressed as mean. For the Acute Toxicity Test, determination of dose tolerance between $2000 \mathrm{mg} / \mathrm{kg}$ BW and $5000 \mathrm{mg} / \mathrm{kg}$ BW was technically observed.

\section{RESULTS}

\section{Physicochemical analysis}

\section{Organoleptic characteristics}

The physical characteristics of both G. parviflora powder and tisane brew are evaluated based on their organoleptic features. The powdered form is light green, having a soft and flaky texture. It has an intensely aromatic scent and a grassy taste.

The tisane brew emits a rich grassy scent having a golden yellow appearance. It has no strong taste and is not bitter; though, slightly salty. It's different from the conventional tea, Camellia sinensis, as it does not have an astringent effect. Technically, it's more like a soup as it does not have a sharp, puckering mouth feel.

\section{Physical properties}

The sample's ash values, extractable content, $\mathrm{pH}$, moisture content, and flowability characteristics are determined, and the results are presented in Table 1. The sample has a particle size of greater than 425 micrometers, not passing sieve 40, US standard. ${ }^{25}$ The low acid-insoluble ash denotes the low presence of silicaceous substances, while higher water-soluble ash shows cellulosic substances. The determination of extractable matter using two solvents, alcohol and water, revealed that water has a

Table 1A: Physical characteristics.

\begin{tabular}{lll}
\hline Particle Size & Sieve Particle size & Value $>\mathbf{4 2 5} \mu \mathrm{m}$ \\
\hline Ash values & Total Ash & $17.23 \%$ \\
& Acid-insoluble Ash & $0.45 \%$ \\
& Water-soluble Ash & $6.38 \%$ \\
Extractable Matter & Water-extractable Content & $71.11 \mathrm{mg} / \mathrm{g}$ \\
& Alcohol-extractable Content & $18.19 \mathrm{mg} / \mathrm{g}$ \\
$\mathbf{p H}$ & $1 \%$ & 6.55 \\
& $10 \%$ & 6.15 \\
Moisture Content & Loss on Drying & $5 \%$
\end{tabular}

Table 1B: Physical characteristics - flow property. *United States Pharmacopoeia, 2016, Powder Flow, pages $2 \& 4^{28}$.

\begin{tabular}{lccc}
\hline Parameter & $\begin{array}{c}\text { Actual } \\
\text { Value }\end{array}$ & Reference Value & Character \\
\hline Compressibility Index & 28 & $26-31$ & Poor $^{*}$ \\
Hausner's Ratio & 1.39 & $1.35-1.45$ & Poor $^{*}$ \\
Angle of Repose & 47.99 & $46-55$ & Poor $^{*}$
\end{tabular}

Table 2: Leaf constants of Galinsoga parviflora.

\begin{tabular}{ll}
\hline \multicolumn{1}{|c}{ Leaf Constant } & Value per square $\mathrm{mm}$ \\
\hline Stomatal number & $4-7$ \\
Stomatal Index & 12.70 \\
Palisade Ratio & 2.78 \\
Vein Islet Number & 3.6 \\
Vein Termination Number & 3.2
\end{tabular}


greater extractive value. This then suggests that water can extract more phytoconstituents on an exhaustive scale between the two solvents.

Natural products like crude herbal materials are prone to microbial growth and contamination; moisture must be kept low to deter the growth of unwanted microbes like fungi that could affect the quality and safety of the product. Significantly, the sample contains an acceptable ${ }^{26}$ amount of moisture which indicates a good standing on storage. Nevertheless, care should be taken in storing dried and powdered herbal materials to prevent microbial growth and contamination.

Powder flow is essential as it determines the ability of the powder material to undergo pharmaceutical processes. Generally, a powder's flowability can be measured using compendial methods such as angle of repose, bulk and tapped density, Carr's Index, and Hausner's ratio to predict its behavior in unit operations such as blending and compression filling, and transportation. ${ }^{27-28}$ The sample's poor flow character is reasonable considering that the sample is for infusion. A poor flowability suggests the herbal powder's poor aggregation and compressibility, allowing better solvent penetration. Thus, better extraction of phytochemicals is achieved.

\section{Botanical evaluation}

\section{Macroscopic characteristics}

G. parviflora is a noxious weed, erecting $22-32$ centimeters $(\mathrm{cm})$, having a multi-branched stem and white and yellow floret. The flower consists of five white disk florets surrounding a pitted yellow ball flower having a size of $0.33 \times 0.48 \mathrm{~cm}$ (Figure 1A). Its leaf is exstipulate, serrated lanceovate to ovate arranged pinnately compound measuring $5.07 \mathrm{~cm}$ long and $3.43 \mathrm{~cm}$ wide with an acuminate apex and a rounded base. Both the upper and lower leaf surfaces are strigose but pilose on the stem. The hair vestiture is almost equal on both surfaces. The abaxial side's hairs mostly rise on the vein network, while those in the adaxial side are within the vein islet (Figure 1B). The pilosity of the stem becomes denser as it reaches the apical part (Figure 1C). The leaves are primarily petiolate with $1.26 \mathrm{~cm}$ length, having a primary vein network, palmate; though, becomes sessile towards the apical part.

\section{Microscopic characteristics}

Visual inspection is subjectively judged, and substitutes or adulterants may closely resemble the genuine product; thus, they should be substantiated with additional tests such as macromorphology, micromorphology, and histological examinations. ${ }^{29}$ Therefore, while organoleptic evaluation provides a simple and fast way to identify and assess the plant material, further characterization and analysis are essential.

\section{Surface microscopy}

The leaves of G. parviflora on both surfaces are covered with a nonglandular, unbranched trichome. The stomata are of anomocytic type (Figure 2A-B). On magnification, it is seen that the non-glandular, filiform trichomes have a slightly broadened base and a pointed tip (Figure 2C). Further, they are septate with 3-5 uniseriate cells measuring up to $7 \mathrm{~mm}$ long and $1 \mathrm{~mm}$ wide.

Both sides of the epidermis are composed of uniseriate, rectangular, continuous epidermal cells having an anticlinal wall and externally covered by a thin cuticle. The mesophyll is dorsiventral, forming one layer of compactly arranged palisade cells and 2-3 layers of spongy parenchyma cells arranged linearly and randomly (Figure 3A).

The midrib is biconvex in outline with a round base and an oval projection at the upper portion (Figure 3B). Notably, the major portion is composed of ground tissue, mainly consisting of parenchyma cells. Clusters of angular collenchyma cells occur along with the upper and lower epidermis, which are finely arranged in both the adaxial and abaxial sides. The vascular system in the midrib consists of an arcshaped single collateral vascular bundle with xylem toward the adaxial side and compacted phloem toward the abaxial side. At the midrib section, a centrally located vascular bundle with 5-7 rows of vertically running 2-5 xylem vessels that are almost similar in size is present.
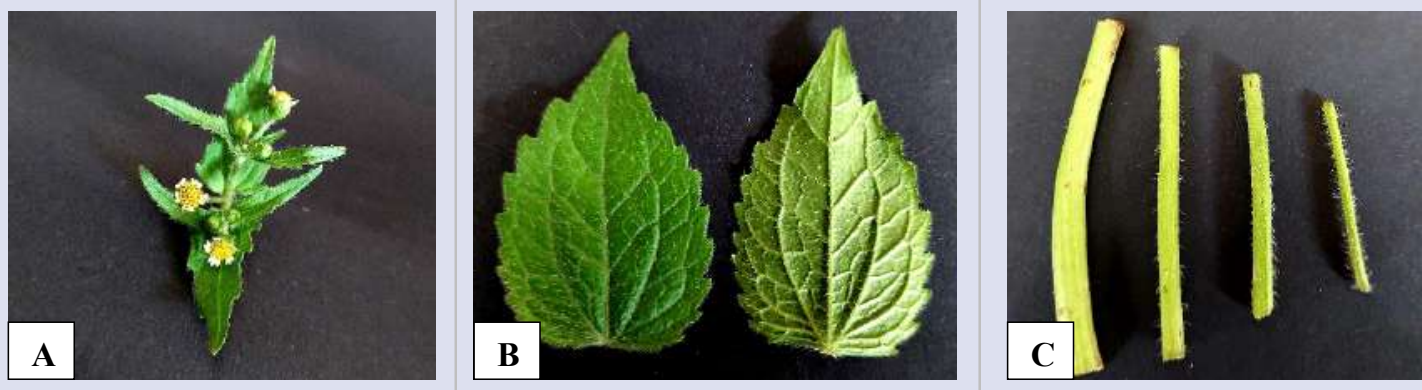

Figure 1: Plant parts. A. Flower; B.(Left) Adaxial leaf side, (Right) Abaxial leaf side; C. Left-Right: Mature to young stem.
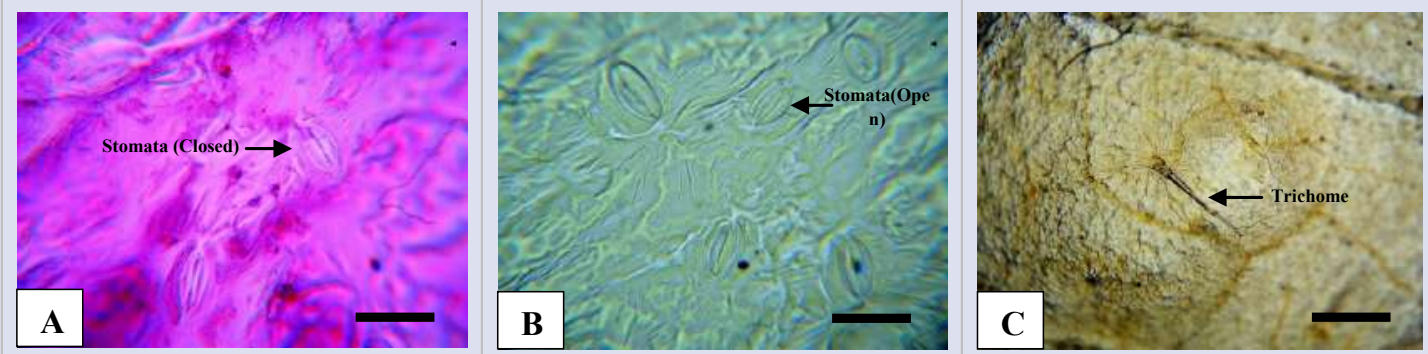

Figure 2: Surface characteristics. Anomocytic Stomata 400x (Stained); B. Anomocytic Stomata 400x (Unstained); C. Nonglandular Trichome. Bars:A-B. $74 \mu \mathrm{m} ;$ C. $0.62 \mathrm{~mm}$. 


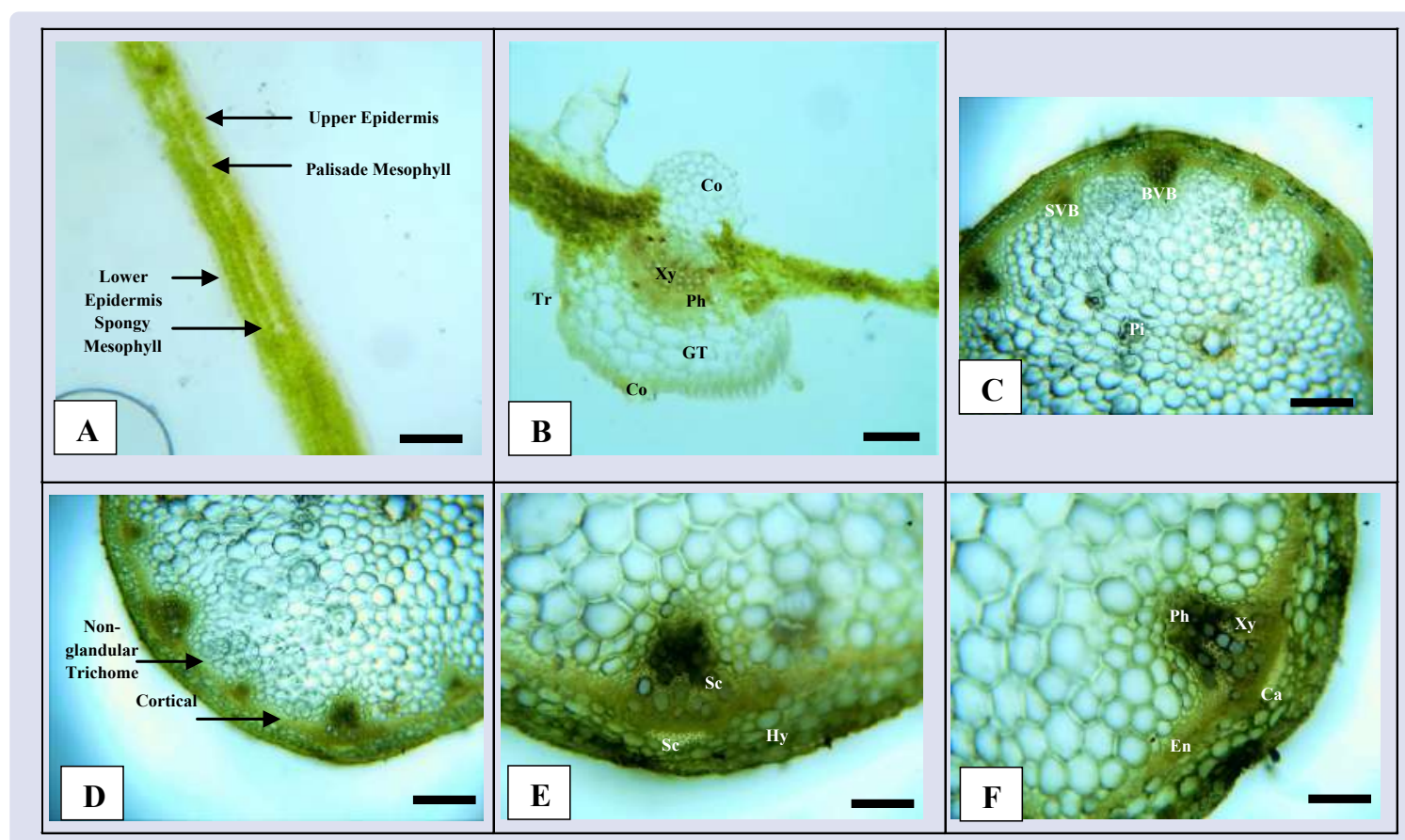

Figure 3: Leaf and stem cross-section:40x (A-D), 100x (E-F). Mesophyll; B.Midrib; Co: Collenchyma, GT: Ground Tissue, Ph: Phloem, Tr: Trichome, Xy: Xylem. C \&D.General View of the Stem; SVB: Small Vascular Bundle, BVB: Big Vascular Bundle, Pi: Pith;

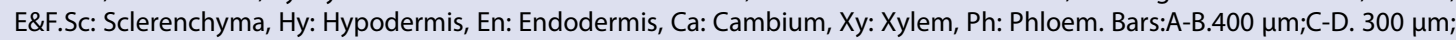
E-F. $200 \mu \mathrm{m}$.
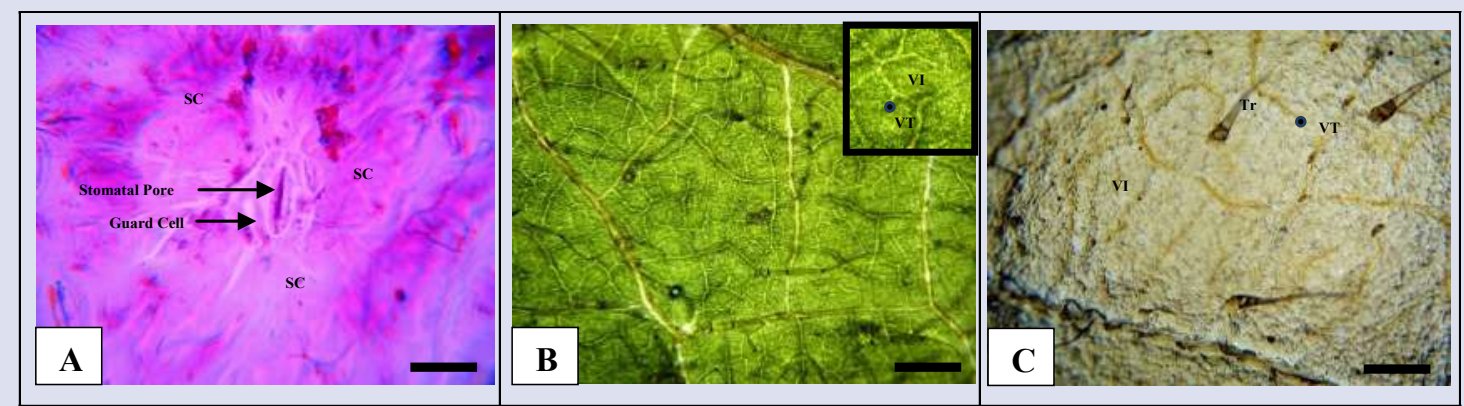

Figure 4: Stomata and vein-islet. A. Stomata 400x (Stained); SC: Subsidiary Cells; B-C.Vein Network; VT: Vein Termination, VI:

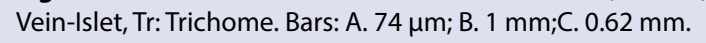

The cross-section of the mature stem shows a circular outline with a well-developed secondary structure (Figure 3C-F). It is composed of 12 vascular bundles, which are alternating in size. The epidermis is a single layer of rectangular cells covered with a thin cuticle layer and a limited number of non-glandular trichomes. The hypodermis comprises 2-3 layers of angular collenchyma cells, while the cortex is composed of a thin layer of parenchyma cells. Markedly, the sclerenchyma cells extend beyond the endodermis, and the cambium aligns along the cortical border. The plant has a bicollateral vascular bundle where compactly arranged condensed phloem cells are found capped above the xylem. Xylem vessels are arranged in rays which is evident for bigger vascular bundles; though, each bundle consists of relatively big vessel elements. The central part of the stem is occupied by a large portion of circular to polygonal parenchyma cells with little to no intercellular space.

\section{Leaf constants}

The leaf constants particularly, the palisade ratio, vein-islet, vein termination, stomatal number, and stomatal index, are measured, and the results are presented in Table 2. G. parviflora leaf surface shows an anomocytic type of stomata (Figure $4 \mathrm{~A}$ ) with an average stomatal index of 12.70. The leaf microscopy shows a simple and curved vein structure where the vein-islet is distinct, lacking a definite pattern and dimension (Figure 4B-C).

Anomocytic stomata are similar to the study's findings conducted by Rivera et al. ${ }^{30}$ and in conflict with the one shown by El-Shabasy\& Al-Gifri. ${ }^{31}$ This can be attributed to the difference in the geographic location to which plants were collected. With reference to the study conducted by Casson \& Gray $^{32}$ on stomatal development, changes in the environment appear to modulate the development and patterning pathways of plants to determine the stomatal frequency. Their study revealed that light intensity and carbon dioxide $\left(\mathrm{CO}_{2}\right)$ concentrations had been shown to influence the frequency at which stomata develop on leaves in several species. This is attributed to long-distance signaling mechanisms with the conditions sensed by mature leaves determining the stomatal frequency in developing leaves. This finding is supported by Qi \& Torri, ${ }^{33}$ wherein apart from secreted peptides and chemical hormones, environmental factors, primarily light, carbon dioxide, and water, influence stomatal development as feedback mechanisms. Technically, the three variables affect plant receptors, hormones, and pathways altering stomatal differentiation and subsequent development. 
Table 3: Histochemical analysis. (+) Positive, the element is present; (-) Negative, the element is absent.

\begin{tabular}{|c|c|c|c|c|c|}
\hline No & Element Tested & Observation & $\mathrm{S}$ & $\mathbf{L}$ & $\mathbf{F}$ \\
\hline 1 & Cellulose cell walls & Blue to blue-violet coloration & + & + & + \\
\hline 2 & Lignified cell walls & Red-purplish red & + & + & + \\
\hline 3 & Suberized cell walls & Red to orange-red coloration & + & + & + \\
\hline 4 & Aleurone grains & Brick-red coloration & + & + & + \\
\hline 5 & Calcium carbonate & Dissolves with effervescence & + & + & + \\
\hline 6 & Calcium oxalate & Insoluble in acetic acid but dissolves in $\mathrm{HCl}$ and $\mathrm{H}_{2} \mathrm{SO}_{4}$ & + & + & + \\
\hline 7 & Fats and oils & Red coloration & + & + & + \\
\hline 8 & Hydroxyanthraquinone & Red coloration & - & + & + \\
\hline 9 & Inulin & Brownish red coloration then dissolves & + & + & + \\
\hline 10 & Mucilage & Blue-violet coloration & + & + & + \\
\hline 11 & Starch & Blue or reddish-blue coloration & - & - & - \\
\hline 12 & Tannin & Bluish black or greenish-black & - & - & - \\
\hline
\end{tabular}

Table 4: Preliminary phytochemical screening. (+) Positive, detected in the Test applied; (-) Negative, not detected in the test applied.

\begin{tabular}{lll}
\hline Plant Constituent & Aerial Part & Observed effect \\
\hline $\begin{array}{lll}\text { Primary Metabolites } \\
\text { Carbohydrates }\end{array}$ & ++ & \\
Proteins & ++ & Precipitation and coloration \\
Fats and Oils & ++ & Coloration \\
Secondary Metabolite & & Stain and soap formation \\
Alkaloids & ++++ & \\
Cardiac Glycosides & ++ & Precipitation \\
Terpenoids & + & Coloration \\
Anthraquinone Glycosides & ++ & Coloration \\
Flavonoids & +++ & Coloration \\
Saponins & ++ & Coloration and precipitation \\
Phytosterols & ++++ & Foam formation and retention \\
Tannins & -+ & Coloration and ring formation
\end{tabular}

Table 5: Acute toxicity test. M: Male; F: Female; D/P: Number of deaths per population; NOE: No observed effect.

\begin{tabular}{|c|c|c|c|c|}
\hline $\begin{array}{l}\text { Dose Administered } \\
\text { (mg/kg BW) }\end{array}$ & Sex & $D / P$ & Toxicological Effect & $\begin{array}{c}\text { Gross Pathological } \\
\text { Changes }\end{array}$ \\
\hline \multirow{2}{*}{2000} & M & $0 / 5$ & NOE & NOE \\
\hline & $\mathrm{F}$ & $0 / 5$ & NOE & NOE \\
\hline \multirow{2}{*}{5000} & M & $0 / 3$ & NOE & NOE \\
\hline & $\mathrm{F}$ & $0 / 3$ & NOE & NOE \\
\hline
\end{tabular}

This concept would explain the difference between stomata observed and the stomatal density and index computed.

\section{Histochemical screening}

Histochemical analysis revealed the presence of a lignified, suberized, and cellulosic cell wall. Notably, hydroxyanthraquinone is absent in the stem. All three parts contain aleurone grain, calcium carbonate, calcium oxalate, fats, oils, inulin, and mucilage (Table 3).

\section{Powder microscopy}

The following diagnostic characters of the plant's flower, leaves, and stem were found during the powder microscopy;

The plant's flower contains a white and yellow disk floret. On powder analysis, the flower has longer, bi- to tetracellular, uniseriate, non-glandular trichomes than those found in the leaves and stem. A feather-like cellulosic fiber is notable among other fiber elements (Figure 5C). Additionally, a pitted vessel, parenchyma cell, spiral xylem vessel, and epidermal cells are also observable, along with the pollen grains present in the pollen sac.

Stem microscopy presents mostly clusters of ground tissues and fiber elements. A broader but bigger trichome is observed as compared to the ones observed in the flowers. Parenchyma and epidermal cells are also spotted along with the annular, scalariform, and spiral xylem vessels.

In comparison, leaf microscopy presents surface epidermal arrangement, fibers, trichomes, and ground tissues. Arrangement of anomocytic stomata is seen from the epidermal surface along with parenchymatous cells. Non-glandular, uniseriate trichomes, which are longer than the stem trichomes but shorter than the flowers' are also observed. A reticulate vessel is present, and a cluster of fiber tissues, parenchymatous cells, and trichome fragments is also seen (Figure 7F).

Phytochemicals are naturally present in plants integral in natural defense against external attacks, such as insect bites and other mechanical, chemical, and environmental stress conditions. Summary of the evaluation of the phytoconstituents, primary and secondary metabolites, of Galinsoga parviflora that were screened is provided in Table 4. Technically, the screening for the type of phytoconstituents present was based on chemical reactions between the reagents and the chemical structure of the metabolite present, which yields distinct coloration of the solution or precipitation of the product from the chemical reaction.

The plant extract yielded positive results from the tests conducted, indicating that primary metabolites -carbohydrates, proteins, fats, and 


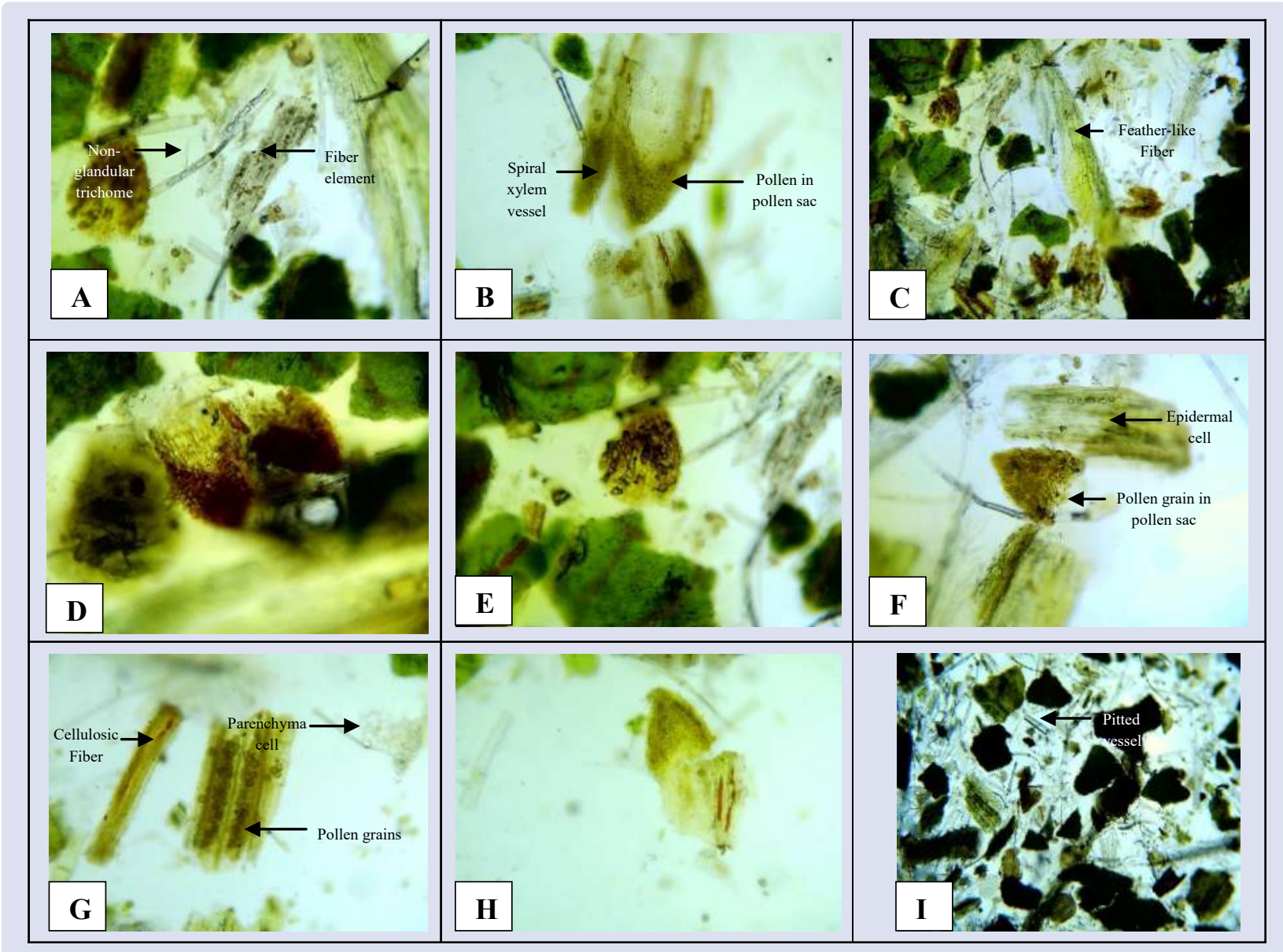

Figure 5: Powder microscopy of G. parviflora flower. Trichome and fiber elements; B. Xylem vessels, parenchyma cells, pollens; C. Fiber elements; D-F. Pollen, epidermal cells, and fiber elements; G. Cellulosic fiber, parenchyma cells, pollens; H. Pollens, vessel element, I. Vessel and fiber elements.

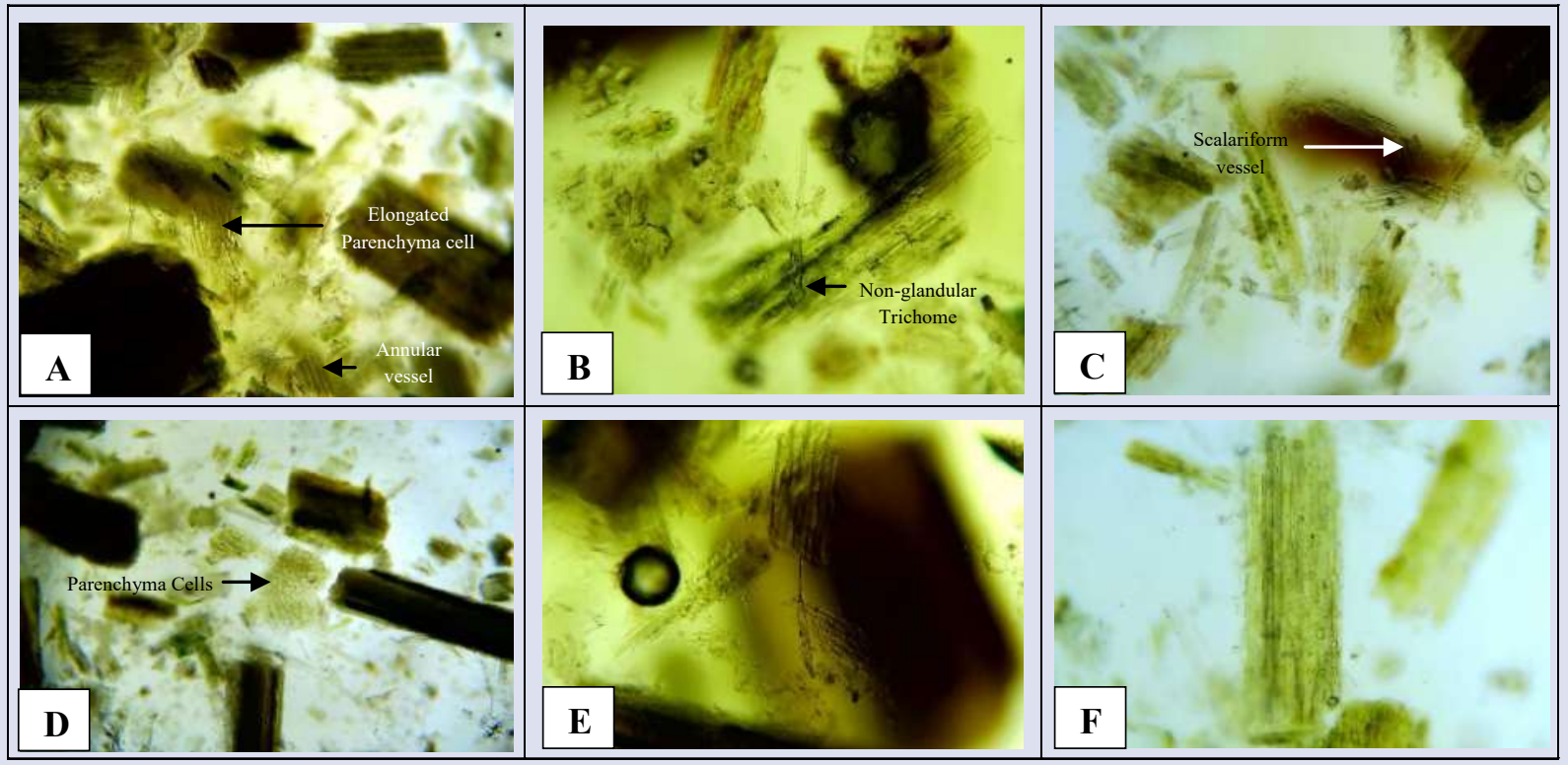

Figure 6: Powder microscopy of G. parviflora stem. A. Parenchyma cells, vessel element; B. Trichome, epidermal cells, C. Vessel and fiber elements, D. Parenchyma cells, E. Parenchyma and surface tissue; F. Surface tissue. 


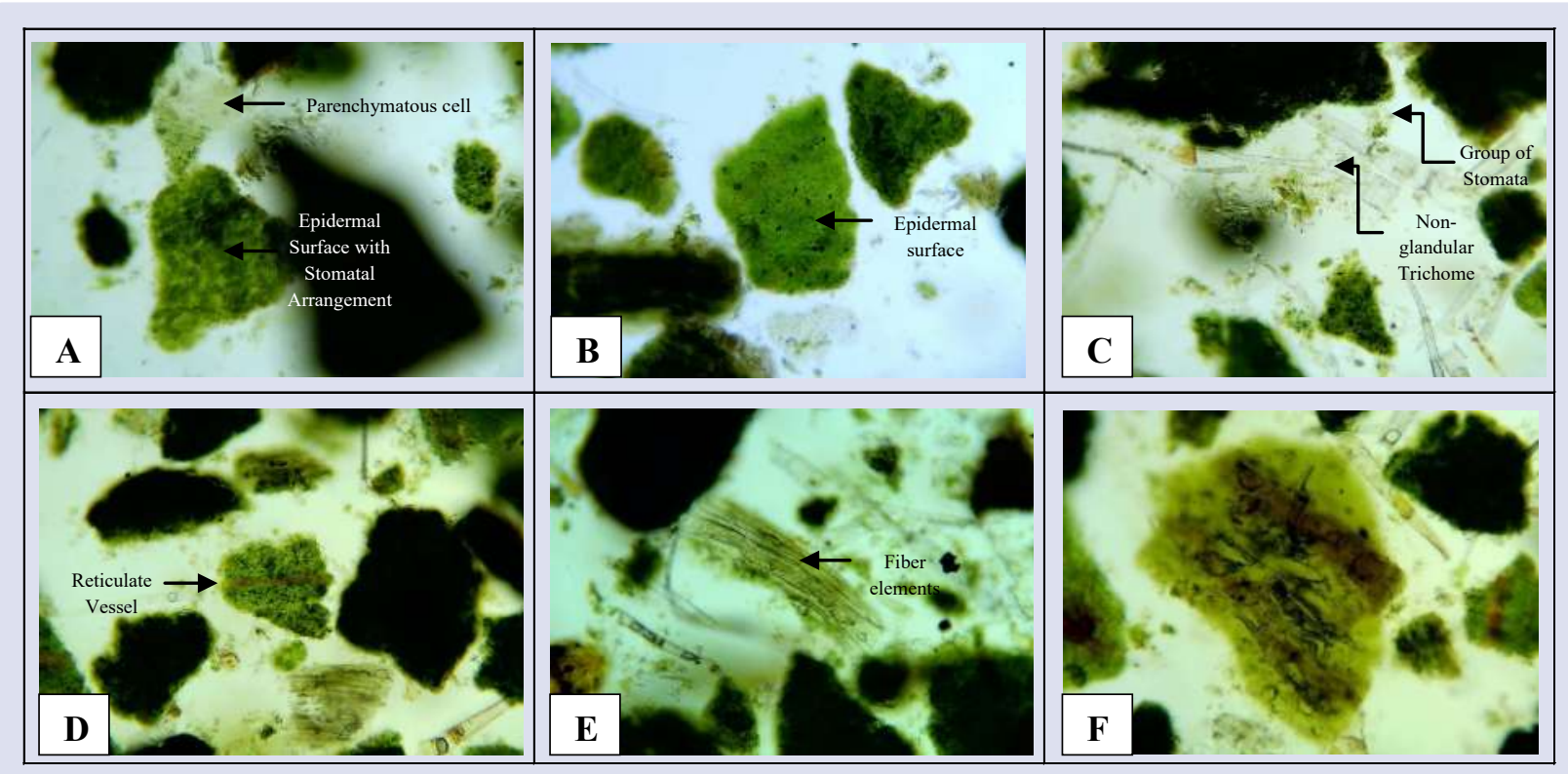

Figure 7: Powder microscopy of G. parviflora leaves. A. Epidermal surface, parenchyma cells; B. Epidermal surface with stomata; C. Trichome, stomata, fiber elements; D. Vessel element; E. Fiber element, trichome fragment; F. Cluster of fiber elements, surface tissues, trichome fragments.

oils are present in the sample. This is expected since these compounds are synthesized in larger amounts than secondary metabolites. They play an essential role in the plant's metabolic processes, structural framework, nutrition, and overall growth and development.

In contrast to primary metabolites, secondary metabolites usually act as antifeedants or sex attractants; many have no apparent biological role in the plant. ${ }^{22}$ However, this group of compounds has valuable application in the pharmaceutical industry as they act as a framework for drug development or even as immediate medicinal agents. Several groups of phytoconstituents were detected during the qualitative analysis of the sample plant. This includes alkaloids, glycosides, flavonoids, saponins, phytosterols, and tannins. Notably, the gelatin salt test for tannins yielded a negative result. This can be attributed to a lower tannin content, resulting in the lower ability to precipitate the protein, gelatin.

With reference to the review conducted by Ali et al., ${ }^{34}$ flavonoids, aromatic esters, diterpenoids, caffeic acid derivatives, steroids, and phenolics were the dominant chemical constituents present in the plant, G. parviflora. Extraction and detection of these phytoconstituents generally employed non-polar solvents including methanol, ethyl acetate, hexane, butanol, and light petrolatum, and subsequent analysis through column chromatography. Reports utilizing water as extracting solvent are still limited; however, one study revealed more compounds in the aqueous extract than the ethanolic extract. ${ }^{10}$ Further, as the polarity of the extracting solvent increases, more and more phytochemicals are being extracted and detected from the same plant. ${ }^{35}$

The results suggest that water exerts enough extracting capacity to obtain essential phytochemicals from the powdered G. parviflora aerial parts. Nevertheless, further qualitative and quantitative analysis to detect and quantify the metabolites present in the aqueous extract is recommended to identify the exact constituent present in the sample extract and supplement the data obtained in the study.

\section{Acute toxicity test}

The initial oral administration of a single dose of $2000 \mathrm{mg} / \mathrm{kg}$ of $G$. parviflora aqueous extract survived the observation period, indicating that the lethal dose is higher than the administered dose. As the sample is intended for human consumption in the form of tisane, further testing at a dose of $5000 \mathrm{mg} / \mathrm{kg}$ was conducted. Similarly, a dose in this category did not cause mortality, evident toxicologic response, and gross pathological changes. All 16 rats (8 female and eight male) survived until the end of the observation period. Additionally, gross pathological examination of the organs did not present significant morphological changes relative to the administration of the test extract (Table 5). The confirmation for the absence of toxicological effect and gross pathological changes for the organs observed were consulted and approved by a veterinarian with expertise in assessing toxicological response and gross anatomical anomalies.

This suggests that the plant contains low to no poisonous substances enough to cause toxicological effects and architectural organ change in rats. Further, this information supports its edibility as food since the result did not yield significant issues in its safety. Additionally, this finding adds to its safety studies initially conducted, where a methanolic extract of the same plant did not show significant toxicity under the acute toxicity test at dose $3200 \mathrm{mg} / \mathrm{kg} .{ }^{36}$ Although the initial safety test of the aqueous extract of $G$. parviflora suggests a safe herbal powder material; further studies must be conducted to strengthen and support its safety profile and use as an alternative medication.

\section{DISCUSSION}

The advent of technology and the resurgence of herbal medicine have opened the age of medical plurality where both allopathic and complementary or alternative treatment is being used to cater to people's medical needs. Complementary and Alternative Medicine (CAM) implies a broad set of health care practices that is not part of the country's own traditional medicine that can be used together with or in place of conventional medicine but is not fully integrated into the dominant healthcare system. ${ }^{5,37}$ In comparison, traditional medicine is the total of the knowledge, skill, and practices based on the theories, beliefs, and experiences indigenous to different cultures used in the maintenance of health and prevention, diagnosis, improvement, or treatment of physical and mental illness. ${ }^{5}$ The majority of each practice revolves around the application of herbal plants and medicine. Currently, its application and preparation have evolved to include encapsulated plant materials and isolated plant extracts. Its upsurge in patronage and use can be attributed to being natural, flexible, and 
considered more effective and safer by most people. However, issues on substitution and adulteration of herbal preparations with other plant materials remain.

Further, herbal formulations are not deemed safe just because it is natural. Some can cause tissue or cellular alteration that may not manifest physically as toxic signs and symptoms. Several literatures have reported irrefutable cases of poisoning with the use of untested, adulterated, contaminated, and even untainted herbal preparations, including hepatotoxicity, nephrotoxicity, cardiotoxicity, splenic enlargement, and even death. ${ }^{8,38-40}$ In this regard, the concept of quality and safety in herbal preparations is challenged. Accordingly, quality standards should be in place, and toxicity tests must be conducted whether the candidate medicine is of herbal or synthetic form as safety is paramount on all substances being taken into the body.

Standardization of herbal medicine is the process of prescribing a set of standards or inherent characteristics, constant parameters, definitive qualitative and quantitative values that assure quality, efficacy, safety, and reproducibility. ${ }^{41}$ It takes into account all aspects that contribute to the quality of the herbal drugs namely, the correct identity of the sample, organoleptic evaluation, pharmacognostic evaluation, volatile matter, quantitative evaluation (ash values, extractive values), phytochemical evaluation, test for the presence of xenobiotics, microbial load testing, toxicity testing, and biological activity. ${ }^{29}$ This is vital as traditional medicine is gaining momentum to a more global and bulk production.

Galinsoga parviflora is commonly known as the Gallant Soldier of the family Asteraceae. It is folklorically used to treat dermatological conditions like eczema, rash brought about by lichens, insect and animal bites, stop bleeding, cold sores, and flu..$^{34}$ It is considered edible as it is being eaten raw, mixed in soups and salads, indicating that the plant is non-toxic. ${ }^{11,42}$ In this present study, the plant's pharmacognostic and safety is presented to establish diagnostic parameters ensuring its identity, quality, purity, and safety as raw material for herbal preparation.

The physical parameters for a particular plant are almost constant, which helps set an appropriate standard for a crude drug. ${ }^{43}$ Thus, the physical parameters obtained in the study, particularly the ash value, extractable matter, $\mathrm{pH}$, moisture content, and powder flowability limits, aids in detecting purposeful adulteration or contamination of the herbal preparation by determining significant variation from the values obtained.

Since herbal preparations are prone to substitution with other botanical agents, a supplemental analysis should be conducted. Botanical characterization allows the elucidation of a plant's morphological and microscopic features, which helps identify and authenticate the plant material correctly. Organoleptic, morphometric, microscopic, and histochemical test results gathered in the study augment the physical and chemical properties of the sample plant. Generally, the parameters obtained by macroscopic and microscopic analysis serve as quality standards in evaluating crude drugs to assure their authenticity, preventing adulteration and substitution. ${ }^{44-46}$

As the search for new drugs continues, plants still occupy a large proportion as baseline materials in this area. Identifying phytoconstituents present in a sample plant is vital since this provides information on the pharmacologically active metabolite used for biological analysis, potential clinical application, and subsequent drug development. The metabolites detected are useful in investigating the plant's pharmacological activity as this provides an initial understanding of the possible biological or pharmacological effect. Such information lays down useful information in assessing the plant material for further pharmaceutical processing such as metabolite isolation, purification, and processing or as crude drug powder in the form of capsule and tisane. Further, it provides information that could support its folkloric use to treat various health conditions once tested and adequately assessed clinically.

The utilization of herbal products in addressing health conditions is rising. This can be traced to increasing advocates and advertisements that herbal medicine, originating from nature, has no toxin or adverse effect, and people can take it long-term. ${ }^{47}$ As a result, some people would disregard the possible connection between herbal use and signs of toxicity. Thus, as with any other commercially and tested drug products, herbal materials should be evaluated the same. Toxicity tests assess behavioral changes, hematological and biological irregularity, histological and pathological anomalies relative to drug administration, serving as an interface for hazard identification and safety evaluation. ${ }^{48-50}$

The development of new drugs relying purely on modern technology appears to be reaching its limit (p.2).$^{5}$ Additionally, the management of diseases with synthetic drugs can produce serious side effects and financial burdens regarding health services like remuneration for health care professionals, laboratory charges, and medications. Further, mass media endorsement and advertisements for herbal products with no scientific justification and mainly based on assumptions are misleading people to its use. Given these circumstances, people continue to utilize and favor herbal products with scarce scientific validation and minimal to no quality standard preparation. Thus, standardization is vital to set quality and safety parameters to assure purity and safety in view of the increasing commercialization of herbal products.

\section{CONCLUSION}

It is undeniable that plants occupy a portion of people's lives. The parameters obtained, supplementing initial reports for the plant species studied, are significant in establishing pharmacopoeial standards, including the botanical and physicochemical criteria for adequate identification and authentication of genuine herbal plant material The pharmacognostic profile of the plant is essential in developing standards for identification and authentication, quality control, and purity assurance, especially in the field of plant-based medicine.

Water as a solvent of choice for extracting essential phytochemical compounds, including alkaloids, glycosides, flavonoids, saponins, phytosterols, and tannins, reinforce the dosage form of the herbal drug as tisane powder for infusion. Data gathered concludes that water is enough to extract vital compounds with biological importance as antibacterial, anti-fungal, anti-oxidant, anti-inflammatory, and cytotoxic agents. This suggests the potential use of G. parviflora for medicinal and nutraceutical purposes, providing an avenue for pharmacological screening, especially for future drug discovery, particularly in traditional, Complementary, and Alternative medicine.

Additionally, the oral dose of up to $5000 \mathrm{mg} / \mathrm{kg}$ of the aqueous extract of G. parviflora showed no significant evidence of treatment-related toxicity and mortality; therefore, the $\mathrm{LD}_{50}$ is presumed to be higher. With reference to the Loomis Classification, the high dose of the plant extract is considered to be practically non-toxic. The traditional use of this plant for various illnesses, especially in decoction or infusion as tea, is implied to be safe; though, further testing should still be carried out.

\section{ACKNOWLEDGMENT}

The authors wish to offer their gratitude to Dr. Ana B. Mendoza, Dr. Jones T. Napaldet, Dr. Danni Lou O. Manuel for their professional assistance, and Dr. Elizabeth L. Tangangco, Dr. Richard P. Dumapis and Dr. Louisa P. Pladio for their kind permission to utilize their institutions' facility.

\section{CONFLICTS OF INTEREST}

None 
Badilla JG, et al.: Pharmacognostic Evaluation and Acute Toxicity Test of the Formulated Tisane Powder of Gallant Soldier (Galinsoga parviflora Cav., Asteraceae) Aerial Parts from Benguet, Philippines

\section{FUNDING}

The study was supported by a grant from the Department of Science and Technology (DOST) under the DOST-Science Education Institute (SEI) Science and Technology Regional Alliance of Universities for National Development (Project STRAND) Program.

\section{REFERENCES}

1. Builders PF. Introductory Chapter: Introduction to Herbal Medicine. In: Builders PF, editor. Herbal Medicine. 2018.

2. Wachtel-Galor S, Benzie IFF. Chapter 1: Herbal Medicine. In: Benzie IFF, Wachtel-GalorS, editors. Herbal Medicine: Biomolecular and Clinical Aspects. $2^{\text {nd }}$ edition. Florida: Taylor \& Francis. 2011.

3. Singh M, Pathak K. Animal Models for Biological Screening of Antidiabetic Drugs: An Overview. European Journal of Experimental Biology. 2015;5(5):37-48.

4. Chan K, Guerry A, Balvanera P, Klain S, Satterfield T, Basurto X, et al. Where are Cultural and Social in Ecosystem Services? A Framework for Constructive Engagement. BioScience. 2012;62(8):744-756.

5. World Health Organization. WHO global report on traditional and complementary medicine 2019. Geneva: World Health Organization. 2019.

6. Tabasum S, Khare S, Jain K. Establishment of Quality Standards of Abrusprecatorius Linn. Seed. Indian Journal of Pharmaceutical Science. 2018;80(3):541-546.

7. World Health Organization. Quality Control Methods for Herbal Materials. Geneva: World Health Organization. 2011.

8. Ekor M. The Growing use of Herbal Medicines: Issues Relating to Adverse Reactions and Challenges in Monitoring Safety. Frontiers in Pharmacology. 2013;4:177.

9. Omprakash B, Shivraj S, Swamy V, Sachin G, Padmaja G, Mahesh B. Standardization and Quality Evaluation of Herbal Drugs. Journal of Drug Delivery and Therapeutics. 2019;9:1058-1063.

10. Bazylko A, Borzym J, Parzonko A. Determination of In-vitro Antioxidant and UV- protecting Activity of Aqueous and Ethanolic Extracts from Galinsoga parviflora and Galinsoga quadriradiata Herb. Journal of Phytochemistry and Photobiology B: Biology. 2015;149:189-195

11. Dudek M, Dudkowski L, Bazylko A, Kazmierski S, Kiss A. Caffeic Acid Derivatives Isolated from the aerial parts of Galinsoga parviflora and their Effect on Inhibiting Burst in Human Neutrophils. Phytochemical Letters. 2016;16:303-310.

12. Ferheen S, Rehman A, Afza N, Malik A, Iqbal L, Rasool M, et al. Galinsosides A and B, Bioactive Flavanonve Glucosides from Galinsoga parviflora. Journal of Enzyme Inhibition and Medicinal Chemistry. 2009;24(5):1128-1132.

13. Mostafa I, El-aziz E, Hafez S, El-shazly A. Chemical Constituents and Biological Activities of Galinsoga parviflora Cav. (Asteraceae) from Egypt. Verlag der ZeitschriftfürNaturforschung. 2013;68:285-292.

14. Parzonko A, Kiss A. Caffeic Acid Derivatives Isolated from Galinsoga parviflora Herb Protected Human Dermal Fibroblasts from UVARadiation. Phytomedicine. 2019;57:215-222.

15. Studzinski-Sroka E, Dudek-Makuch M, Chanaj-Kaczmarek J, Czepulis N, Korybalska K, Rutkowski R, et al. Anti-inflammatory Activity and Phytochemical Profileof Galinsoga Parviflora Cav. Molecules. 2018;23:2133.

16. Dar R, Shahnawaz M, Qazi P. General overview of medicinal plants: A review. The Journal of Phytopharmacology. 2017;6(6):349-351.

17. Knevel A, DiGangi F. Jenkin's Quantitative Pharmaceutical Chemistry. $7^{\text {th }}$ edition. New York: McGraw-Hill, Inc; 1977;223-236.

18. World Health Organization. WHO Guidelines on Herbal Processing Practices for Herbal Medicines. Annex 1. World Health Organization. 2018.
19. World Health Organization. Bulk Density and Tapped Density of Powders. World Health Organization. 2012

20. United States Pharmacopoeia. Bulk Density and Tapped Density of Powders. USP. 2015;30(6)

21. Evans W. Trease and Evans Pharmacognosy. $16^{\text {th }}$ edition. New York: Saunders Elsevier; 2009;537-570.

22. Aguinaldo AM, Espeso El, Guevarra BQ, Nonato MG Phytochemistry. In: Guevarra BQ, editor. Philippines: Research Center for the Natural Sciences. 2004.

23. De S, Dey YN, Ghosh AK. Phytochemical Investigation and Chromatographic Evaluation of the Different Extracts of Tuber of Amorphaphalluspaeoniifolius (Araceae). International Journal on Pharmaceutical and Biomedical Research. 2010;1(5):150-157.

24. Organization for Economic and Co-operative Development. Test No. 425: Acute Oral Toxicity: Up-and-Down Procedure. Organization for Economic and Co-operative Development. 2008

25. United States Pharmacopoeia. Particle Size Distribution Estimation by Analytical Sieving. USP. 2016;30(6).

26. A\&D Company. Moisture Analyzer: Manual. Japan: A\&D Company, Limited. 2014.

27. Etti C, Yusof $Y$, Chin N, Tahir SM. Effects of Formulation on Flowability of Selected Herbal Powders using Compendial Methods and Powder Flow Analyser. International Food Research Journal. 2016;23:225-230.

28. United States Pharmacopoeia. Powder Flow. USP. 2016;30(6).

29. Bijauliya R, Alok S, Chanchal D, Kumar M. A Comprehensive Review on Standardization of Herbal Drugs. International Journal of Pharmaceutical Sciences and Research. 2017;8(9):3663-3677.

30. Rivera P, Terrazas T, Rojas-Leal A, Villaseñor J. Leaf Architecture and Anatomy of Asteraceae Species in a Xerophytic Scrub in Mexico City, Mexico, Acta Botanica Mexicana. 2019;126:e1515.

31. El-Shabasy A, Al-Gifri A. Vegetative Anatomy of Galinsoga parviflora Cav. (A Newly Recorded Genera in Jazan Region, KSA). Journal of Agriculture and Life Sciences. 2019;(2):2375-4214.

32. Casson S, Gray J. Influence of Environmental Factors on Stomatal Development. New Phytologist. 2007;178:9-23.

33. Qi X, Torii K. Hormonal and Environmental Signals Guiding Stomatal Development. BMC Biology. 2018;16:21.

34. Ali S, Zameer S, Yaqoob M. Ethnobotanical, Phytochemical, and Pharmacological Properties of Galinsoga parviflora (Asteraceae): A Review. Tropical Journal of Pharmaceutical Research. 2017;16(12):3023-3033.

35. Kannan PJ. Phytochemical analysis of Gallant soldier (Galinsoga parviflora) Cav. (Asteraceae) from Nilgiris of India. International Journal of Research in Pharmacy and Pharmaceutical Sciences. 2017;2(4):76-78.

36. Yadav AK, Tangpu V. Therapeutic Efficacy of Bidens pilosa L. var radiata and Galinsoga parviflora Cav. in Experimentally Induced Diarrhoea in Mice. Phytopharmacology \& Therapeutic Values. 2008;23.

37. National Institute of Health. Complementary, Alternative, or Integrative Health: What's In a Name? National Center for Complementary and Integrative Health. National Institute of Health. 2018.

38. Farrington R. Herbal medicine toxicity: The role of adulterants, contaminants and pharmacokinetic interactions. Dissertation. University of Adelaide. 2019.

39. Fatima N, Nayeem N. Toxic Effects as a Result of Herbal Medicine Intake. In: Soloneski S, Larramendy ML, editors. Toxicology - New Aspects to This Scientific Conundrum. 2016. 
40. Shulammithi R, Sharanya M, Tejaswini R, Kiranmai M. Standardization and Quality Evaluation of Herbal Drugs. IOSR-Journal of Pharmacy and Biological Sciences. 2016;11(5):2278-3008.

41. Sachan A. Need of Standardization of Herbal Medicines in Modern Era. International Journal of Phytomedicine. 2016;8:300-307.

42. Damalas C. Distribution, Biology, and Agricultural Importance of Galinsoga parviflora(Asteraceae). Weed Biology and Management. 2008:8:147-153.

43. AlamF, Saqib QN. Pharmacognostic standardization and preliminary phytochemical studies of Gaultheria trichophylla. Pharmaceutical Biology. 2015;53(12):1711-1718.

44. Akbar S, Hanif U, Ali J, Ishtiaq S. Pharmacognostic studies of stem, roots and leaves of Malva parviflora L., Asian Pacific Journal of Tropical Biomedicine 2014;4(5):410-415

45. Amponsah I, Mensah A, Otoo A, Mensah M, Jonathan J. Pharmacognostic standardisation of Hilleria latifolia (Lam.) H. Walt. (Phytolaccaceae). Asian Pacific Journal of Tropical Biomedicine. 2014;4(12):941-946.
46. Kumar S, Kumar V, Prakash O. Microscopic evaluation and physiochemical analysis of Dillenia indica leaf. Asian Pacific Journal of Tropical Biomedicine. 2011;1(5):337-340.

47. Zhang J, Onakpoya I, Posadzki P, Eddouks M. The Safety of Herbal Medicine: From Prejudice to Evidence. Evidence-Based Complementary and Alternative Medicine. 2015; 3.

48. Balogun F, Ashafa A. Acute and Subchronic Oral Toxicity Evaluation of Aqueous Root Extract of DicomaanomalaSond. In Wistar Rats. Evidence-Based Complementary and Alternative Medicine. 2016;11.

49. Kpemissi M, Metowogo K, Melila M, Veerapur $\bigvee$, Negru M, Taulescu $\mathrm{M}$, et al. Acute and subchronic oral toxicity assessments of Combretum micranthum (Combretaceae) in Wistar rats. Toxicology Reports. 2020;162-168.

50. Vutukuri V, Das M, Reddy M, Prabodh S, Sunethri P. Evaluation of Acute Oral Toxicity of Ethanol Leaves Extract of Catharanthus roseus in Wistar Albino Rats. Journal of Clinical and Diagnostic Research. 2017;11(3):FF01-FF04.

51. Yuan H, Ma Q, Ye L, Piao G. The Traditional Medicine and Modern Medicine from Natural Products. Molecules. 2016;21:559.

\section{GRAPHICAL ABSTRACT}
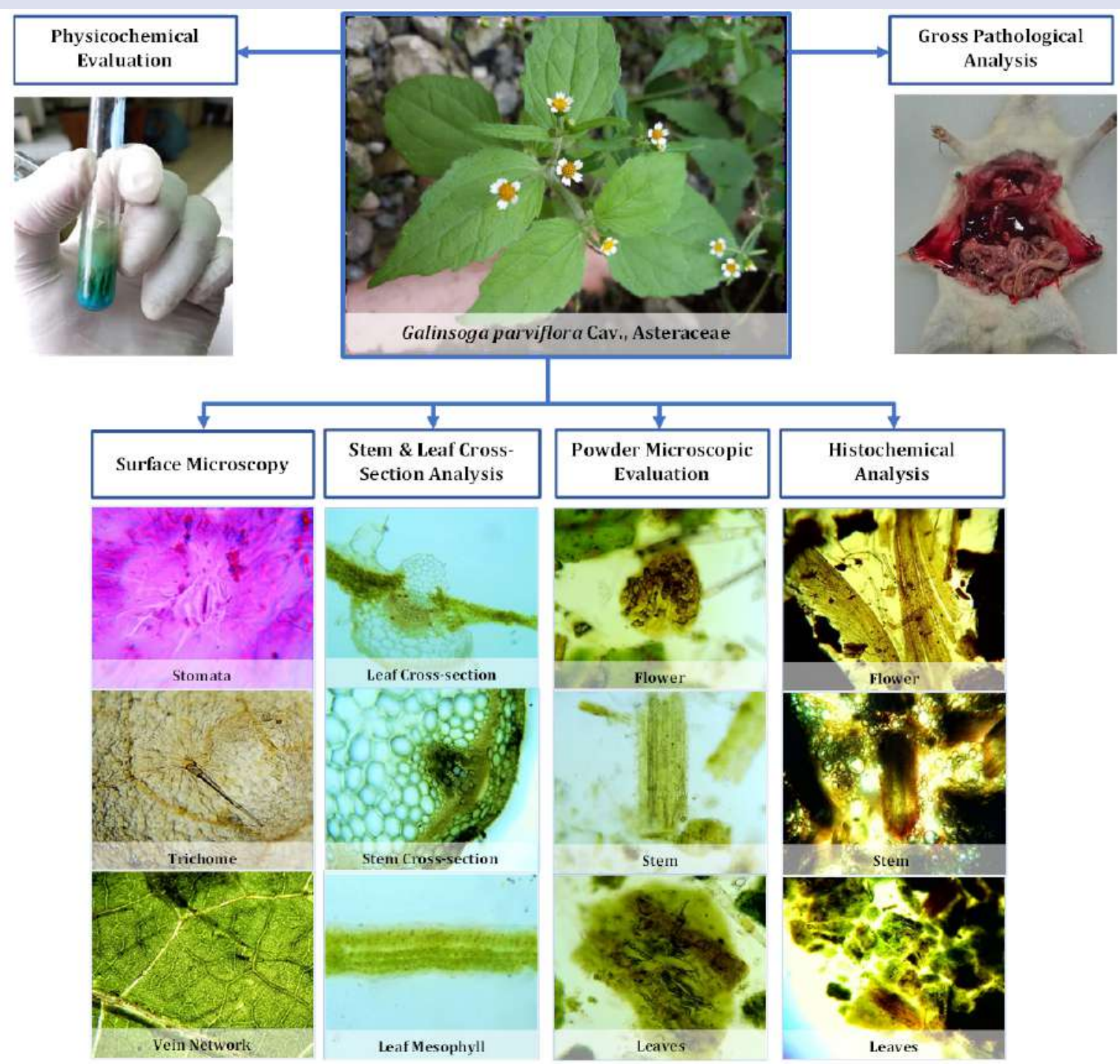


\section{ABOUT AUTHORS}

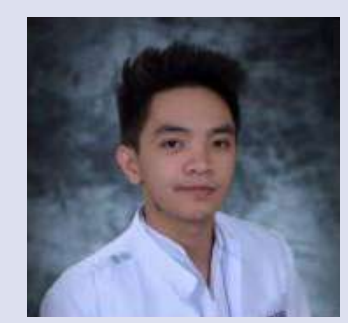

Joniever Guanso Badilla is a graduate student of the School of Advanced Studies at Saint Louis University, Baguio City, Philippines, and an instructor of the Pharmacy Program in the School of Natural Sciences on the same school. His research interests are inclined towards the development of alternative medications, bio-insecticides, and botanical agents for real-time use.

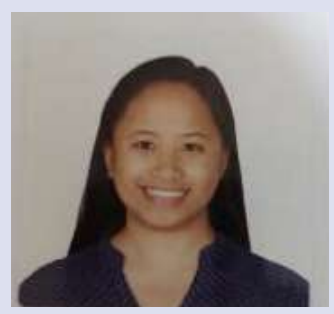

Mary Luz C. Fiangaan is an Associate Professor in the Department of Pharmacy, School of Natural Sciences at Saint Louis University, Baguio City, Philippines. Her field of specialization is geared towards Pharmaceutical Education and Practice and Natural Products Development.

Cite this article: Badilla JG, Fiangaan MLC. Pharmacognostic Evaluation and Acute Toxicity Test of the Formulated Tisane Powder of Gallant Soldier (Galinsoga parviflora Cav., Asteraceae) Aerial Parts from Benguet, Philippines . Pharmacogn J. 2022;14(1): 193204. 